\title{
The functions of belly-soaking in Kentish Plovers Charadrius alexandrinus
}

\author{
JUAN A. AMAT ${ }^{1 *} \&$ JOSE A. MASERO ${ }^{2}$ \\ ${ }^{1}$ Estación Biológica de Doñana, C.S.I.C., Apartado 1056, E-41080 Sevilla, Spain \\ ${ }^{2}$ Departamento de Biología Animal, Universidad de Extremadura, E-06071 Badajoz, Spain
}

\begin{abstract}
We tested whether belly-soaking (i.e. wetting of ventral plumage) in incubating Kentish Plovers Charadrius alexandrinus in a hot environment serves to cool overheated eggs, or whether belly-soaking would mainly serve for adult thermoregulation, and egg wetting would be a mere consequence of the ventral feathers of incubating adults being wet. When ambient temperature was high $\left(>30{ }^{\circ} \mathrm{C}\right)$, body temperature of incubating Kentish Plovers increased with ambient temperatures. When adults departed from nests to belly-soak, egg temperatures were not critical for embryos. However, eggs in exposed nests overheated to levels that may be lethal for embryos when adults left the nests to belly-soak, and adults also employed belly-soaking to cool down overheated eggs when they returned to their nests. Indeed, the cooling rate of eggs was much faster when they were wetted. We conclude that the primary function of belly-soaking in the Kentish Plover is to dissipate body heat in heat-stressed incubating adults, rather than to cool overheated eggs. Eggs overheated as a consequence of short-term interruptions in nest attendance by heat-stressed adults to belly-soak, and Plovers employed secondarily belly-soaking to cool down overheated eggs. These results indicate that adult thermoregulation and egg cooling are not mutually exclusive functions of belly-soaking.
\end{abstract}

While incubating eggs in hot environments, individuals of many species have to face heavy heat loads (e.g. Grant 1982), and to mitigate thermally stressful conditions they deploy behavioural and physiological strategies (Purdue 1976, Grant 1982, Downs \& Ward 1997, Amat \& Masero 2004b). One of such behavioural strategies is belly-soaking (i.e. wetting of ventral plumage), which has been recorded in a number of pterocliform (sandgrouses) and charadriiform (shorebirds, terns and gulls) species (Maclean 1974, Grant 1981, 1982), as well as in a passerine bird (Jackson \& Schardien 1981). Belly-soaking is limited to the breeding season, and differs from bathing behaviour in that only the belly feathers are wetted either by walking into relatively deep water and flexing the legs, or simply by walking through deep water and wetting the ventral feathers (Maclean 1974, Grant 1982). Belly-soaking in the sandgrouse is associated with the transport of drinking water for the chicks (Maclean 1974, Reynolds 1985), but especially in

*Corresponding author.

Email: amat@ebd.csic.es shorebirds, gulls and terns its main function has been suggested to be thermoregulatory, either of the birds themselves or of their eggs (see below). Grant (1982) showed that the average number of belly-soaks per hour in Black-necked Stilts Himantopus mexicanus increased dramatically with ambient temperature, from three at $25-30{ }^{\circ} \mathrm{C}$ to more than 100 at $>35{ }^{\circ} \mathrm{C}$. Shorebirds may move up to $100 \mathrm{~m}$ from their nests to water sources to belly-soak (Reynolds 1985).

Maclean (1974) considered as belly-soaking the 'deliberate wetting of the ventral plumage for the purpose of water transport to eggs or young' (see also Howell 1979, Rogers \& Eades 1997). Drent (1975), however, thought that belly-soaking would mainly serve for adult thermoregulation, and that egg wetting would be a mere consequence of the ventral feathers of incubating adults being wet. Nevertheless, circumstantial evidence from the behaviour of adults at nests suggests that belly-soaking may have both, non-mutually exclusive, functions (Grant 1982, Reynolds 1985, Kalsi \& Khera 1986). On one hand, the fact that belly-soaking is affected by proximity to water (Reynolds 1985, Bergstrom 1989), and that 
nest desertion by shorebirds is higher in sites far from water (Amat \& Masero 2004b), suggests that belly-soaking may facilitate nest attentiveness by adults under hot conditions ( $>35{ }^{\circ} \mathrm{C}$; Grant 1982, Amat \& Masero 2004b). In addition, only the ventral region is wetted when shorebirds belly-soak (Begg \& Maclean 1976, Grant 1982, Kalsi \& Khera 1986), which may be related to the role of the abdominal air sacs in body temperature $\left(T_{b}\right)$ regulation (Cowles 1965, Schmidt-Nielsen et al. 1969). On the other hand, when ambient temperature is $>30{ }^{\circ} \mathrm{C}$ adults stand on the nests instead of sitting on the eggs (Maclean 1967, Grant 1982, Downs \& Ward 1997, Amat \& Masero 2004b), and when they leave the nests to belly-soak, there is a sudden increase in egg temperature if eggs remain exposed to direct sunlight; but when adults return to their nests they lower their wet belly feathers onto the eggs, resulting in a drop in egg temperature (Schardien \& Jackson 1979, Grant 1982). Despite this evidence, study of the function of belly-soaking (egg cooling vs. adult thermoregulation) has not been specifically addressed.

In this paper we tested whether the primary function of belly-soaking is to cool overheated eggs, as proposed by Maclean (1974), or whether belly-soaking serves for adult thermoregulation, as proposed by Drent (1975). For this, we conducted an observational and experimental study on Kentish Plovers Charadrius alexandrinus nesting in a hot environment. This species is ideal for such a study because most of its nests are in sites with no or little cover (Grant 1982, Page et al. 1985, Amat \& Masero 2004a), and thus receive direct sunlight, rendering the adults susceptible to heat stress (Purdue 1976, Grant 1982, Amat \& Masero 2004b) and the eggs to overheating (Grant 1982). A prediction derived from Maclean's (1974) hypothesis is that incubating adults should depart from nests to belly-soak once a threshold of egg temperature that compromises embryo survival is reached. However, if adults depart from nests to belly-soak before such a threshold is reached, the main function of belly-soaking would be adult thermoregulation. This is likely if, as shown in other bird species (Weathers 1981, Ellis et al. 1995, Ward \& Pinshow 1995), the body temperature of Kentish Plovers increases when ambient temperature is

$>30{ }^{\circ} \mathrm{C}$, so that they would resort to belly-soaking as a mechanism to dissipate quickly excess body heat. However, egg temperatures may reach lethal levels while the nests are left unattended by adults, in which case a secondary function of belly-soaking would be to cool overheated eggs. Therefore, if eggs overheat during parental absences from the nest, the adults should wet the eggs to cool them when resuming nest attendance. Hence, we recorded both egg and body temperatures of Kentish Plovers to test whether belly-soaking serves to control egg temperature, adult body temperature or both.

\section{METHODS}

\section{Birds and body temperatures}

The study was conducted at Fuente de Piedra lake in southern Spain $\left(37^{\circ} 06^{\prime} \mathrm{N}, 4^{\circ} 45^{\prime} \mathrm{W}\right)$, described in Amat et al. (1999). At this lake, Kentish Plovers mainly nest in exposed sites, and have to face stressful thermal conditions during incubation (Amat \& Masero 2004a, 2004b). Using walk-in traps, we captured Plovers ( $n=68$ individuals) at their nests throughout the day (04:45-19:30 h, GMT) to record $T_{\mathrm{b}}$. Only one measurement was taken per individual. Upon capture, we inserted a thin (36-gauge) copperconstantan thermocouple probe (Omega Engineering, Inc., Stamford, CT, USA) into the cloaca, and $T_{\mathrm{b}}$ was measured to the nearest $0.1{ }^{\circ} \mathrm{C}$ with an Omega HH21 microprocessor thermometer. These probes and those used to record egg temperatures (see below) were calibrated to the nearest $0.1{ }^{\circ} \mathrm{C}$ against a standard thermometer. Air temperature was measured $5 \mathrm{~cm}$ above ground level $\left(T_{\mathrm{a} 5}\right)$ immediately after we took $T_{\mathrm{b}}$. The range of $T_{\mathrm{a} 5}$ throughout the day was wide, and this allowed us to show whether the Plovers increased $T_{\mathrm{b}}$ with $T_{\mathrm{a} 5}$ under natural conditions.

\section{Belly-soaking and egg temperatures}

To ascertain whether belly-soaking contributed to cooling the eggs, we performed an experiment on sunny days. We had previously collected eggs from deserted nests, emptied them and filled them with plaster of Paris. We placed a Kentish Plover egg filled with plaster of Paris in each of 13 empty nests of Kentish Plovers that were in exposed sites. About $50 \mathrm{~cm}$ from each one of these natural nests, scrapes of similar size to those of Kentish Plovers were made in exposed sites, into which we added pebbles and small twigs to resemble natural nests, and also placed in each one of these hand-made nests an egg filled with plaster of Paris. We used eight model eggs that we alternated among nests. We left the eggs in each pair of nests shaded for $10 \mathrm{~min}$, after which we removed the shade and left them exposed to direct 
sunlight for $3 \mathrm{~min}$. Because when $T_{\mathrm{a} 5}$ is $>30{ }^{\circ} \mathrm{C}$ Kentish Plovers in exposed nests usually do not sit, but instead stand over the eggs (Amat \& Masero 2004b), this procedure allowed us to simulate shortterm interruptions in nest attendance by adults (see Grant 1982, for durations of natural interruptions in nest attentiveness to belly-soak). After this, we shaded the eggs again for another 10-min period, and at the same time that the eggs were shaded, one of the eggs was wetted by using a brush soaked in water. The excess of water in the brush was allowed to wet the nest material, as occurs under natural conditions (Howell 1979, Grant 1982). The other egg was not wetted.

Temperatures of eggs filled with plaster of Paris $\left(T_{\text {egg }}\right)$ were recorded with Omega 36-gauge copperconstantan thermocouple probes inserted into the eggs. The thermal conductance of plaster of Paris $(0.432 \mathrm{~W} / \mathrm{m} / \mathrm{K}$, Weast (1986) cited in Ward (1990)) is almost identical to that of natural eggs $(0.43 \mathrm{~W} / \mathrm{m} / \mathrm{K}$, Henderson (1963) cited in Ward (1990)). $T_{\mathrm{a} 5}$ was measured at an exposed site $\sim 1 \mathrm{~m}$ from the natural nest with a 20-gauge probe, with its tip covered with white reflective tape (Ward 1990). All probes were connected to Omega OM-550 dataloggers, which were programmed to record temperatures every $40 \mathrm{~s}$ between 12:00 and 15:00 h, the hottest part of the day (Amat \& Masero 2004b). Egg temperatures were averaged for each one of the periods (shaded, exposed and shaded again) and categories (egg wetted, egg not wetted). The lowest $T_{\mathrm{a} 5}$ when we conducted this experiment was $32.2{ }^{\circ} \mathrm{C}$, which may not be high enough to elicit belly-soaking (see Results). However, our aim with this experiment was simply to show whether there were differences in $T_{\text {egg }}$ depending on the possibility of belly-soaking, and whether cooling rates of overheated eggs after short-term interruptions in nest attendance were higher when they were wetted than when they were not wetted.

\section{Ambient temperatures and belly-soaking}

To study under which $T_{\mathrm{a} 5}$ the Kentish Plovers resorted to belly-soaking, we placed containers filled with water $\sim 3 \mathrm{~m}$ from five active nests, which were located $>300 \mathrm{~m}$ from the nearest natural source of water. These containers had a diameter of $14 \mathrm{~cm}$ and a height of $3 \mathrm{~cm}$. We substituted one of the eggs in the nests by a Kentish Plover egg filled with plaster of Paris. $T_{\text {egg }}$ and $T_{\mathrm{a} 5}$ were recorded every $40 \mathrm{~s}$ between 12:00 and 15:00 $\mathrm{h}$ as indicated above. Departures of incubating plovers from nests to belly-soak were inferred from sharp increases in $T_{\text {egg }}$ when nests were left unattended, and belly-soaking was inferred from sharp decreases in $T_{\text {egg }}$ when adults returned to their nests (Schardien \& Jackson 1979; see also Amat \& Masero 2004a). Although Kentish Plovers could leave the nest for reasons other than belly-soaking when $T_{\mathrm{a} 5}$ was high, we think that this rarely occurred during our study for three reasons. First, when $T_{\mathrm{a} 5}$ is high, shorebirds are reluctant to leave their nests unattended, even when intruders approach the nests, and if they leave the nests the adults return very quickly to them (Maclean 1967, our pers. obs.). Secondly, nearly $90 \%$ of disturbances of incubating Kentish Plovers at our study site are due to Gullbilled terns Gelochelidon nilotica ( $n=229$; Amat \& Masero 2004a), but during the hottest periods of the day the Terns are rarely active (our pers. obs.). Thirdly, when Kentish Plovers left their nests, their operative temperatures were likely to be high (see Discussion), suggesting that they could have left the nests for thermoregulatory purposes.

We recorded $T_{\text {egg }}$ every time that the incubating adults departed from nests (i.e. when $T_{\text {egg }}$ started to rise), the maximum $T_{\text {egg }}$ each time the nest was unattended while the adult was belly-soaking, and minimum $T_{\text {egg }}$ every time the adults returned from belly-soaking. In addition, about $50 \mathrm{~cm}$ from each one of the natural nests, scrapes of similar size to those of Kentish Plovers were made in exposed sites, and we placed in each one of these hand-made nests an egg filled with plaster of Paris with the aim of recording $T_{\text {egg }}$ in nests that were continuously unattended. $T_{\mathrm{a} 5}$ was measured at an exposed site $\sim 1 \mathrm{~m}$ from the natural nests. Because the plovers usually belly-soaked several times during recording periods, we averaged each category of data (i.e. $T_{\text {egg }}$ every time that the incubating adults departed from nests, maximum $T_{\text {egg }}$ each time the nest was unattended while the adults were belly-soaking, and minimum $T_{\text {egg }}$ every time after the adults returned from bellysoaking) for each of the five nests, so that in statistical analyses sample sizes represent nests and not total number of observations. We did not record the sex of the incubating adult.

To confirm whether the adults of these nests belly-soaked, we noted whether the eggs were wet in subsequent visits to the nests, and/or the incubating adults were observed with matted belly feathers when they departed from nests (see Grant 1982).

When we substituted natural eggs with Kentish Plover eggs filled with plaster of Paris, natural eggs 
were placed in nearby nests for the duration of the experiments $(3 \mathrm{~h})$. The natural eggs were returned to their original nests once the experiment had finished. Hatching success was not affected by this procedure (Amat \& Masero 2004b).

\section{RESULTS}

\section{Body temperatures and ambient temperatures}

We found that for incubating Kentish Plovers captured throughout the day over a wide range of $T_{\mathrm{a} 5}$ there was a significant relationship between their $T_{\mathrm{b}}$ values and $T_{\mathrm{a} 5}$ (Spearman rank correlation, $r_{\mathrm{s}}=$ $0.42, n=68, P<0.001) . T_{\mathrm{b}}$ of some individuals was about $3{ }^{\circ} \mathrm{C}$ above normal $T_{\mathrm{b}}$ for shorebirds (i.e. $41{ }^{\circ} \mathrm{C}$; McNab 1966, Prinzinger et al. 1991), indicating that they became nearly hyperthermic at high $T_{\mathrm{a} 5}$ (Fig. 1).

\section{Effects of belly-soaking on egg temperatures}

During the first 10 -min period that model eggs were experimentally shaded there were no differences in mean temperatures between the egg that was subsequently wetted ( $T_{\text {wegg }}$ ) and the eggs that were not wetted ( $T_{\text {nwegg }}$ ) (Student's paired $t$-test, $t_{12}=0.64$, ns, Table 1), nor when both categories of eggs were exposed over a 3-min period to direct sunlight (paired $t_{12}=0.11$, ns, Table 1 ). However, when the eggs were shaded again and one was wetted to

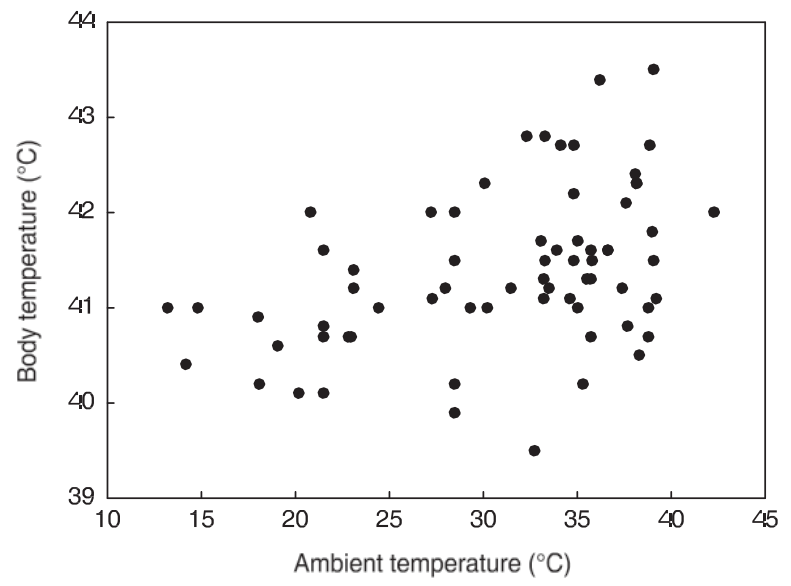

Figure 1. Relationship between the body (cloacal) temperature of incubating Kentish Plovers and the ambient temperature $5 \mathrm{~cm}$ above ground level beside nests.
Table 1. Mean temperatures $\left({ }^{\circ} \mathrm{C} \pm 1 \mathrm{sd}, n=13\right)$ of Kentish Plover eggs filled with plaster of Paris after wetting or not wetting following a short period of overheating.

\begin{tabular}{lccc}
\hline Treatment & Shade 1 & Sun & Shade 2 \\
\hline Egg wetted & $32.7 \pm 3.1$ & $34.2 \pm 2.9$ & $32.5 \pm 2.5$ \\
Egg not wetted & $32.8 \pm 2.8$ & $34.2 \pm 2.7$ & $34.0 \pm 2.5$ \\
Ambient & $34.6 \pm 2.2$ & $34.7 \pm 2.3$ & $34.9 \pm 2.4$
\end{tabular}

The eggs were in nest scrapes located $50 \mathrm{~cm}$ apart, and were shaded for $10 \mathrm{~min}$ (shade 1), then exposed to direct sunlight for 3 min (sun), and then shaded again for 10 min (shade 2). At the same time that the eggs were shaded for a second time, one of them was wetted by using a brush soaked in water, but the other egg was not wetted. Ambient temperature was recorded $5 \mathrm{~cm}$ above ground level and about $1 \mathrm{~m}$ from nests. Temperatures were recorded every $40 \mathrm{~s}$ with thermocouples connected to a datalogger.

simulate belly-soaking, there were highly significant differences between mean $T_{\text {wegg }}$ and $T_{\text {nwegg }}$ over the subsequent $10-\mathrm{min}$ period (paired $t_{12}=4.28, P=$ 0.001, Table 1).

When the eggs were exposed to direct sunlight for 3 min after having been shaded, there was a rise of 1.4-1.5 ${ }^{\circ} \mathrm{C}$ in mean $T_{\text {wegg }}$ and $T_{\text {nwegg }}$ that was highly significant when compared with mean egg temperatures during the previous shaded period (for $T_{\text {wegg }}$ paired $t_{12}=6.35, P<0.001$; for $T_{\text {nwegg }}$ paired $t_{12}=$ 7.02, $P<0.001$; Table 1). When one of the eggs was wetted and shaded again for 10 min, mean $T_{\text {wegg }}$ returned to the original level before it was exposed to direct sunlight (paired $t_{12}=0.71$, ns, Table 1). Indeed, the decrease in $T_{\text {wegg }}$ following soaking was very sharp (Fig. 2). Nevertheless, if one of the eggs was shaded again, but not wetted, mean $T_{\text {nwegg }}$ did not return to the original level before it was exposed to direct sunlight. In fact, its mean temperature was similar to that recorded when it was exposed to direct sunlight (paired $t_{12}=1.29$, ns, Table 1 ). There were no differences in mean $T_{\mathrm{a} 5}$ among the three periods (Table 1). Consequently, belly-soaking may serve to cool down eggs that are overheated as a result of short-term interruptions in nest attendance by adults.

\section{Ambient temperatures and belly-soaking}

We confirmed directly that belly-soaking occurred at four of the five nests in which we supplied a container with water either by direct observations of belly-soaking (one nest), adults with matted belly feathers (three nests) and/or wet eggs (two nests). 


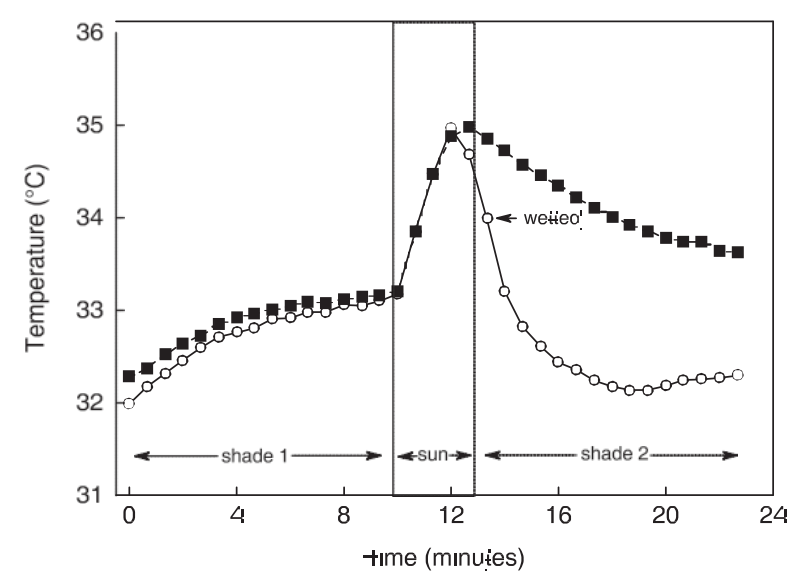

Figure 2. Effects of simulated belly-soaking on temperatures of pairs of model Kentish Plover eggs filled with plaster of Paris (means of 13 pairs, standard errors are not presented for clarity). Temperatures were recorded every $40 \mathrm{~s}$ with thermocouples inserted into the eggs and connected to a datalogger. Every pair of eggs was in nest scrapes located $50 \mathrm{~cm}$ apart. The eggs were shaded for $10 \mathrm{~min}$ (shade 1), then exposed to direct sunlight for $3 \mathrm{~min}$ (sun), and then shaded again for $10 \mathrm{~min}$ (shade 2). At the same time that the eggs were shaded for a second time, one of them was wetted (indicated by arrow) by using a brush soaked in water, but the other egg was not wetted.

We inferred belly-soaking in the five nests by variations in $T_{\text {egg. }}$. Mean (sd) $T_{\text {a } 5}$ when incubating adults departed from their nests to belly-soak was $40.0 \pm$ $1.7{ }^{\circ} \mathrm{C}(n=5)$ (range of all observations at the five nests was $36.8-43.6{ }^{\circ} \mathrm{C}$ ). $T_{\text {egg }}$ was $37.7 \pm 1.2^{\circ} \mathrm{C}$ when the adults departed from their nests to belly-soak. As the nests remained exposed to direct sunlight when adults were belly-soaking, $T_{\text {egg }}$ rose to $40.3 \pm 3.5{ }^{\circ} \mathrm{C}$ during the absences of adults. However, when adults returned to their nests and wetted the eggs, $T_{\text {egg }}$ decreased to $36.5 \pm 1.8^{\circ} \mathrm{C}$, which was similar to $T_{\text {egg }}$ when the adults departed from nests to belly-soak (paired $t_{4}=1.24, \quad P=0.476$ ). Thus, under the conditions of this experiment $T_{\text {egg }}$ decreased following wetting, then remained stable during incubation, and it did not begin to increase until the adults left the nests. Mean $T_{\text {egg }}$ in handmade nests that were continuously unattended by adults was $47.6 \pm 3.6{ }^{\circ} \mathrm{C}(n=5)$.

\section{DISCUSSION}

We have shown that when $T_{\mathrm{a} 5}$ increased, $T_{\mathrm{b}}$ of Kentish Plovers incubating in exposed sites also increased. The operative temperature of an animal is the temperature that it experiences as a result of the sum of air temperature and any temperature increment or decrement that results from radiative and convective factors (Bakken 1976). Using an equation presented in Amat and Masero (2004b) for Kentish Plovers attending nests in standing posture in exposed sites, we determined that, for the range of $T_{\mathrm{a} 5}$ over which Kentish Plovers were observed to belly-soak $\left(36.8-43.6{ }^{\circ} \mathrm{C}\right)$, the operative temperatures experienced by the Plovers would vary from 45 to $54{ }^{\circ} \mathrm{C}$. This implies that heat dissipation mechanisms other than belly-soaking would not be effective in preventing heat gain in Kentish Plovers (see Amat \& Masero 2004b).

Maclean (1974) proposed that the main function of belly-soaking is to cool overheated eggs, but our results on Kentish Plovers did not support his hypothesis. When adult Kentish Plovers left their nests to belly-soak during our study, average $T_{\text {egg }}$ was $37.7^{\circ} \mathrm{C}$. As optimal egg temperatures for embryo development in most Charadriiformes vary from 35 to $38^{\circ} \mathrm{C}$ (Drent 1975, Grant 1982, Rahn 1991), our results indicate that eggs were not overheated, and therefore that embryo survival was not compromised when incubating adults departed from exposed nests to belly-soak. Similarly, Howell and Bartholomew (1962) concluded that, under conditions of intense solar radiation, $T_{\text {egg }}$ in attended Sooty Tern Sterna fuscata nests was unlikely to reach lethal levels. However, as a result of short-term interruptions in nest attendance, $T_{\text {egg }}$ in Kentish Plover nests increased to $40{ }^{\circ} \mathrm{C}$. Although this temperature was much lower than that reached by unattended exposed model eggs (about $48{ }^{\circ} \mathrm{C}$ ), it is within lethal limits if maintained for extended periods (Webb 1987). When adults returned to nests after bellysoaking, they wetted their eggs, and in this way they were able quickly to reduce $T_{\text {egg }}$ to within the limits tolerable for developing embryos. Howell (1979) and Grant (1982) also found that overheated eggs returned to normal incubation temperatures after being wetted.

Observations of belly-soaking by shorebirds under special circumstances may, however, support Maclean's (1974) hypothesis. Thus, egg wetting has been observed after interruptions in incubation due to disturbances during which eggs remained exposed to direct sunlight (Goutner 1984, Rogers \& Eades 1997), and also seems to be more frequent when nesting substrates readily conduct heat (Roberts 1977, Howell 1979, Schardien \& Jackson 1979, Bergstrom 1989).

In conclusion, our results suggest that the primary function of belly-soaking in Kentish Plovers is to 
dissipate $T_{\mathrm{b}}$ in heat-stressed incubating birds, rather than to cool overheated eggs, as $T_{\text {egg }}$ usually did not reach lethal levels while the nest was attended. Eggs overheated as a consequence of short-term interruptions in nest attendance by heat-stressed adults to belly-soak, and Plovers seemed to employ bellysoaking secondarily to cool down overheated eggs. Indeed, cooling rates of overheated eggs were much higher when moisture was applied to the eggs than when the eggs were not wetted. As our observations were collected during a limited number of days, $T_{\text {egg }}$ remains to be measured during hotter conditions $\left(T_{\mathrm{a} 5}>\right.$ $45^{\circ} \mathrm{C}$ ) than those encountered during our fieldwork. Possibly above some threshold of ambient temperature $T_{\text {egg }}$ increases despite parental attendance, in which case belly-soaking could have a dual function: reducing adult $T_{\mathrm{b}}$ as well as $T_{\text {egg }}$. Therefore, dissipation of body heat in incubating adults and egg cooling are not mutually exclusive functions of belly-soaking.

Because climate may influence a species' spatial distribution through its impacts on thermoregulatory processes (e.g. Hayworth \& Weathers 1984, Root 1988, Kearney \& Porter 2004), our results suggest that in arid and hot regions the availability of flooded sites in which to belly-soak may be an important determinant affecting the placement of nests by shorebirds, and therefore the distribution of nesting habitats. Moreover, the inability of shorebirds to attend their nests under very hot conditions without resorting to belly-soaking episodes may have led species that inhabit arid and hot regions in which water may be in short supply (e.g. some coursers and plovers; Urban et al. 1986) to breed in autumn and winter.

This study was financially supported by Dirección General de Investigación Científica y Técnica (research grant PB95-0110). Fieldwork was authorized by Consejería de Medio Ambiente, Junta de Andalucía, which also provided accommodation. We thank A. Arroyo, R. Camarena, J. M. Ramírez, M. Rendón-Martos, J. Rubio and M. Vázquez for their help during fieldwork. During manuscript preparation we were funded by Dirección General de Investigación with EU-ERDF support (research grant BOS2002-04695). The paper benefited from comments of Tamás Székely and an anonymous referee.

\section{REFERENCES}

Amat, J.A., Fraga, R.M. \& Arroyo, G.M. 1999. Brood desertion and polygamous breeding in the Kentish Plover Charadrius alexandrinus. Ibis 141: 596-607.

Amat, J.A. \& Masero, J.A. 2004a. Predation risk on incubating adults constrains the choice of thermally favourable nest sites in a plover. Anim. Behav. 67: 293-300.
Amat, J.A. \& Masero, J.A. 2004b. How Kentish Plovers, Charadrius alexandrinus, cope with heat stress during incubation. Behav. Ecol. Sociobiol. 56: 26-33.

Bakken, G.S. 1976. A heat transfer analysis of animals - Unifying concepts and application of metabolism chamber data to field ecology. J. Theor. Biol. 60: 337-384.

Begg, G.W. \& Maclean, G.L. 1976. Belly-soaking in the Whitecrowned Plover. Ostrich 47: 65.

Bergstrom, P.W. 1989. Incubation temperatures of Wilson's Plovers and Killdeers. Condor 91: 634-641.

Cowles, R.B. 1965. Hyperthermia, aspermia, mutation rates and evolution. Q. Rev. Biol. 40: 341-367.

Downs, C.T. \& Ward, D. 1997. Does shading behavior of incubating shorebirds in hot environments cool the eggs or the adults? Auk 114: 717-724.

Drent, R.H. 1975. Incubation. In Farner, D.S., King, J.R. \& Parkes, K.C. (eds) Avian Biology, Vol. V: 333-420. New York: Academic Press.

Ellis, H.I., Maskrey, M., Pettit, T.N. \& Whittow, G.C. 1995 Thermoregulation in the Brown Noddy (Anous stolidus). J. Therm. Biol. 20: 307-313.

Goutner, V. 1984. Belly-soaking in the Avocet. Ostrich 55: 167-168.

Grant, G.S. 1981. Belly-soaking by incubating Common, Sandwich, and Royal Terns. J. Field Ornithol. 52: 244.

Grant, G.S. 1982. Avian incubation: egg temperature, nest humidity, and behavioral thermoregulation in a hot environment. Ornithol. Monogr. 30: 1-75.

Hayworth, A.M. \& Weathers, W.W. 1984. Temperature regulation and climatic adaptation in Black-billed and Yellow-billed Magpies. Condor 86: 19-26.

Howell, T.R. 1979. Breeding biology of the Egyptian Plover, Pluvianus aegypticus (Aves: Glareolidae). Univ. Calif. Publ. Zool. 104: 1-76.

Howell, T.R. \& Bartholomew, G.A. 1962. Temperature regulation in the Sooty Tern. Ibis 104: 98-105.

Jackson, J.A. \& Schardien, B.J. 1981. Belly-soaking as a possible thermoregulatory mechanism in nestling Purple Martins. N. Am. Bird Bander 6: 12-13.

Kalsi, R.S. \& Khera, S. 1986. Some observations on breeding and displacement behaviour of the Redwattled Lapwing, Vanellus indicus indicus (Aves: Charadriidae). Res. Bull. (Sci.) Panjab Univ. 37: 131-141.

Kearney, M. \& Porter, W.P. 2004. Mapping the fundamental niche: physiology, climate, and the distribution of a nocturnal lizard. Ecology 85: 3119-3131.

Maclean, G.L. 1967. The breeding biology and behaviour of the Double-banded Courser Rhinoptilus africanus (Temminck). Ibis 109: 556-569.

Maclean, G.L. 1974. Belly-soaking in the Charadriiformes. J. Bombay Nat. Hist. Soc. 72: 74-82.

McNab, B.K. 1966. An analysis of the body temperatures of birds. Condor 68: 47-55.

Page, G.W., Stenzel, L.E. \& Ribic, C.A. 1985. Nest site selection and clutch predation in the Snowy Plover. Auk 102: 347-353.

Prinzinger, R., Preßmar, A. \& Schleucher, E. 1991. Body temperature in birds. Comp. Biochem. Physiol. 99A: 499506.

Purdue, J.R. 1976. Thermal environment of the nest and related parental behavior in Snowy Plovers, Charadrius alexandrinus. Condor 78: 180-185

Rahn, H. 1991. Why birds lay eggs. In Deeming, D.C. \& Ferguson, M.W.J. (eds) Egg Incubation. Its Effects on Embryonic 
Development in Birds and Reptiles: 345-360. Cambridge: Cambridge University Press.

Reynolds, J.F. 1985. Belly-soaking. In Campbell, B. \& Lack, E. (eds) A Dictionary of Birds: 45. Calton: T. \& A. D. Poyser.

Roberts, M.G. 1977. Belly-soaking in the Whitefronted Plover. Ostrich 48: 111-112.

Rogers, D.I.R. \& Eades, D.W. 1997. Belly-soaking and eggcooling behaviour in a Red-capped Plover Charadrius ruficapillus. Stilt 30: 53-54.

Root, T. 1988. Energy constraints on avian distributions and abundances. Ecology 69: 330-339.

Schardien, B.J. \& Jackson, J.A. 1979. Belly-soaking as a thermoregulatory mechanism in nesting Killdeers. Auk 96: 604-606.

Schmidt-Nielsen, K., Kanwisher, J., Lasiewski, R.C., Cohn, J.E. \& Bretz, W.L. 1969. Temperature regulation and respiration in the Ostrich. Condor 71: 341-352.
Urban, E.K., Fry, C.H. \& Keith, S. 1986. The Birds of Africa, Vol. 2. London: Academic Press.

Ward, D. 1990. Incubation temperatures of Crowned, Blackwinged, and Lesser Black-winged Plovers. Auk 107: 10-17.

Ward, D. \& Pinshow, B. 1995. Temperature regulation of the Great Grey Shrike (Lanius excubitor) in the Negev desert - I. Laboratory measurements of metabolic rate and evaporative water loss. J. Therm. Biol. 20: 263-269.

Weathers, W.W. 1981. Physiological thermoregulation in heat-stressed birds: consequences of body size. Physiol. Zool. 54: 345-361.

Webb, D.R. 1987. Thermal tolerance of avian embryos: a review. Condor 85: 874-898. 